\title{
AVALIAÇÃO DE POPULAÇÕES DE POSSÍVEIS RIZOBACTÉRIAS EM SOLOS SOB ESPÉCIES FLORESTAIS $^{(1)}$
}

\author{
Rodrigo Matheus Pereira ${ }^{(2)}$, Érico Leandro da Silveira ${ }^{(2)}$, Lúcia \\ Maria Carareto-Alves ${ }^{(3)} \&$ Eliana Gertrudes de Macedo Lemos ${ }^{(3)}$
}

\begin{abstract}
RESUMO
Embora estudos recentes relatem a utilização de RCPC (Rizobactérias Promotoras de Crescimento de Plantas) no Brasil, raríssimos trabalhos avaliam a presença natural dessas espécies bacterianas no solo. O objetivo deste trabalho foi avaliar a ocorrência de RPCP em duas amostras de solo sob diferentes tipos de manejo, através da construção e do seqüenciamento de bibliotecas de DNA metagenômico. Utilizaram-se oligonucleotídeos específicos para amplificação da região hipervariável do espaço intergênico dos genes ribossomais 16S-23S de DNA extraído de diferentes solos, sob Eucalyptus sp. e sob mata. Os fragmentos obtidos foram inseridos em vetor e clonados. As bibliotecas geraram 495 clones, que foram seqüenciados e identificados através de comparações realizadas pelo software Blast. O solo sob Eucalyptus sp. apresentou maior número de RPCP do que sob mata. Os filos Actinobacteria e Proteobacteria eram maiores no solo sob Eucalyptus sp., estando o filo Firmicutes ausente no solo sob mata. Somente oito espécies diferentes de RPCP foram detectadas: Bacillus subtilis, Bacillus megaterium, Bradyrhizobium japonicum, Bradyrhizobium elkanii, Bradyrhizobium sp., Frankia sp., Pseudomonas fluorescens e Pseudomonas gladioli. O trabalho forneceu valiosos dados sobre a presença de RPCP em solos com espécies florestais e sua possível utilização em reflorestamentos, assim como para o melhor conhecimento desses microrganismos nos solos do Brasil.
\end{abstract}

Termos de indexação: RPCP, ecologia microbiana, Eucalyptus sp., ITS.

\footnotetext{
${ }^{(1)}$ Recebido para publicação em outubro de 2006 e aprovado em agosto de 2008.

${ }^{(2)}$ Doutorando do Curso de Microbiologia Agropecuária da Faculdade de Ciências Agrárias e Veterinárias, Universidade Estadual Paulista - FCAV/UNESP. Rod. Paulo Donato Castellane s/n, CEP 14884-900 Jaboticabal (SP). E-mails: rodrigo@bioinfo.com.br; ericosilveira@gmail.com

(3) Professora de Bioquímica da FCAV, UNESP. E-mails: egerle@fcav.unesp.br; lmcalves@fcav.unesp.br
} 


\title{
SUMMARY: EVALUATION OF POSSIBLE RHIZOBACTERIA POPULATIONS IN SOILS UNDER FOREST SPECIES
}

\begin{abstract}
Although new studies describe the use of PGPR (Plant Growth-Promoting Rhizobacteria) in Brazil, they rarely evaluate the natural existence of these bacterial species in the soil. The objective of this study was to evaluate PGPR in two samples under different use types, one with native forest and the other with eucalyptus, through construction and sequencing of a metagenomic DNA library. Using specific probes from the internally transcribed region of $16 S-23 S$ rRNA genes, fragments of PCR products were inserted into the vector and cloned. The library generated 495 clones, which were sequenced and identified using Blast software. A greater number of PGPR was found in the soil under eucalyptus than under forest. Actinobacteria and Proteobacteria phyla were more abundant in Eucalyptus sp soil, and the phylum Firmicutes was not found in forest soil. Only eight different species were detected: Bacillus subtilis, Bacillus megaterium, Bradyrhizobium japonicum, Bradyrhizobium elkanii, Bradyrhizobium sp., Frankia sp., Pseudomonas fluorescens and Pseudomonas gladioli. This study provided valuable information about $P G P R$ in soils under forest species and their possible used in reforestation, as well as for a more detailed understanding of these microorganisms in Brazilian soils.
\end{abstract}

Index terms: PGPR, microbial ecology, Eucalyptus sp., ITS.

\section{INTRODUÇÃO}

Rizobactérias promotoras de crescimento de plantas (RPCP) representam uma ampla variedade de bactérias do solo, que, em associação com as plantas hospedeiras, resultam na estimulação de seu crescimento.

Estudos recentes relatam a utilização de RPCP no Brasil (Amorim et al., 2002; Freitas et al., 2004, Sottero et al., 2006), entretanto apenas um pequeno número envolve RPCP em árvores, geralmente em Eucalyptus sp. e pinus (Germano et al., 2002; Teixeira et al., 2005) e com enfoque no controle de fitopatógenos. Um amplo estudo de árvores e de RPCP poderia beneficiar o setor florestal e o reflorestamento em diferentes regiões (Lucy et al., 2004). Além disso, o setor florestal constitui um importante segmento econômico no país, ocupando lugar de destaque no PIB brasileiro. Em 2001 contribuiu com 4 bilhões de dólares em exportações (Juvenal et al., 2002). Sendo assim, o estudo com RPCP em florestas torna-se de grande importância.

Há poucos grupos de pesquisadores trabalhando na área de RPCP em espécies florestais e, como conseqüência, há pouco ou nenhum dado para o uso dessas bactérias no desenvolvimento de árvores decíduas e menos ainda para árvores coníferas (Chanway, 1997).

As pesquisas de RPCP em solo sob floresta são bem menos comuns do que as ocorridas em aplicações na agricultura (Lucy et al., 2004). Ao longo da década de 80, o foco dos estudos de RPCP em espécies florestais era voltado para angiospermas, mas durante a década de 90 intensificaram-se as pesquisas com gimnospermas (Chanway, 1997).
Embora algumas árvores se desenvolvam facilmente, muitas apresentam dificuldades de crescimento e estabelecimento até que se tornem adultas, quando podem ser altamente beneficiadas por uma inoculação com RPCP (Zaady \&.Perevoltsky, 1995).

A especificidade de bactérias para a inoculação de espécies florestais parece ser similar à observada em sementes agrícolas (Enebak et al., 1998; Shishido \& Chanway, 2000). Ecotipos ou árvores da mesma espécie, de diferentes regiões ou altitudes, também exibem diferentes respostas à inoculação bacteriana (Chanway, 1995).

Há uma ampla faixa de estirpes bacterianas, como Bacillus polymixa, que consistentemente promove o crescimento de muitas variedades de pinus e outras espécies de árvores (Holl, 1992; Chanway, 1995). É interessante notar que esta estirpe bacteriana foi originalmente isolada de grama perene e não de uma espécie florestal (Holl \& Chanway, 1992).

O objetivo deste trabalho foi verificar a ocorrência de rizobactérias promotoras de crescimento de plantas (RCPC), em amostras de solo sob diferentes tipos de manejo.

\section{MATERIAL E MÉTODOS}

\section{Coleta de material}

As amostras de um Latossolo Vermelho foram coletadas em maio de 2002 em duas áreas localizadas nas dependências da Faculdade de Ciências Agrárias e Veterinárias de Jaboticabal - (FCAV/UNESP - SP . 
Brasil), cujas coordenadas geográficas são: latitude $21^{\circ} 17^{\prime} 05$ " S e longitude $48^{\circ} 17^{\prime} 09^{\prime}$ L e altitude em torno de $590 \mathrm{~m}$. A primeira coleta foi realizada em uma área com mata nativa, não alterada pelo homem e caracterizada pela presença de sub-bosque rico em arbustos. O outro solo foi coletado em uma área de arboreto de Eucalyptus sp., plantado em fevereiro de 1969, que não sofreu trato cultural desde então. De cada solo, foram coletadas doze amostras simples ao acaso, na profundidade de $0-20 \mathrm{~cm}$, abrangendo toda a área. As amostras de cada solo foram reunidas e homogeneizadas, resultando em duas amostras compostas, que foram utilizadas para a extração do DNA metagenômico. Os resultados das análises químicas e granulométricas dos solos das duas áreas são apresentados no quadro 1. A normal de precipitação pluvial da localidade é de $1.408,7 \mathrm{~mm}$ nos últimos trinta anos, e a temperatura média anual é de $22^{\circ} \mathrm{C}$, sendo a média das mínimas $12{ }^{\circ} \mathrm{C}$ e das máximas $32{ }^{\circ} \mathrm{C}$ (Fonte: Estação Agroclimatológica UNESP - Campus Jaboticabal).

Extração de DNA metagenômico, PCR de amplificação e purificação dos amplicons do espaço intergênico da região 16S-23S rRNA (ITS)

A extração do DNA da comunidade microbiana do solo (DNA metagenômico) foi realizada utilizando FastDNAR Spin Kit para solo (Bio 101 - catálogo \#6560-200) conforme as instruções do fabricante.

O DNA metagenômico foi usado na amplificação do espaço intergênico (ITS) 16S-23 S rRNA genes por PCR de acordo com Laguerre et al. (1996). As amostras foram então colocadas em um termociclador, e o seguinte programa foi usado: um ciclo a $94^{\circ} \mathrm{C}$ e submetidas a 35 ciclos a $94^{\circ} \mathrm{C}$ por $1 \mathrm{~min}, 55^{\circ} \mathrm{C}$ por $1 \mathrm{~min}, \mathrm{e} 72^{\circ} \mathrm{C}$ por $30 \mathrm{~s}$, mais uma extensão final de 1 ciclo a $72^{\circ} \mathrm{C}$ por 5 min.

Quadro 1. Resultados de análises químicas e granulométricas do Latossolo Vermelho de mata nativa (SMN) e arboreto com Eucalyptus sp. (SE)

\begin{tabular}{lcc}
\hline \multicolumn{1}{c}{ Característica } & SMN & SE \\
\hline $\mathrm{pH}\left(\mathrm{CaCl}_{2}\right)$ & 6,2 & 5,5 \\
Matéria orgânica $\left(\mathrm{g} \mathrm{dm}^{-3}\right)$ & 75 & 61 \\
$\mathrm{P}\left(\mathrm{mg} \mathrm{dm}^{-3}\right)$ & 63 & 17 \\
$\mathrm{~K}\left(\mathrm{mmol}_{\mathrm{c}} \mathrm{dm}^{-3}\right)$ & 2,9 & 4,8 \\
$\mathrm{Ca}\left(\mathrm{mmol}_{\mathrm{c}} \mathrm{dm}^{-3}\right)$ & 410 & 49 \\
$\mathrm{Mg}\left(\mathrm{mmol}_{\mathrm{c} \mathrm{dm}}{ }^{-3}\right)$ & 80 & 40 \\
$\mathrm{H}+{\mathrm{Al}\left(\mathrm{mmol}_{\mathrm{c}} \mathrm{dm}^{-3}\right)}_{\mathrm{Argila}\left(\mathrm{g} \mathrm{kg}^{-1}\right)}^{15}$ & 28 \\
Limo $\left(\mathrm{g} \mathrm{kg}^{-1}\right)$ & 430 & 440 \\
Areia Fina $\left(\mathrm{g} \mathrm{kg}^{-1}\right)$ & 256 & 120 \\
Areia Grossa $\left(\mathrm{g} \mathrm{kg}^{-1}\right)$ & 130 & 180 \\
Classe textural & 184 & 260 \\
\hline
\end{tabular}

Os amplicons foram analisados por eletroforese com gel de agarose e brometo de etídeo (EBAGE) e eluídos do gel pela adição de $\mathrm{NaCl} 1 \mathrm{~mol} \mathrm{~L}^{-1}$ fenol e clorofórmio (Sambrook \& Russell, 2001).

\section{Clonagem e seqüenciamento do ITS}

Os amplicons do espaço intergênico 16S-23S rDNA de ambas as amostras de solo foram inseridas dentro do pGEM ${ }^{\circledR}$ - T vector (Promega, Madison, WI, USA catalog \# A3600) de acordo com instruções do fabricante, e usados para transformar células de Escherichia coli estirpe DH5a. Bactérias transformadas foram cultivadas em meio LB contendo ampicilina $\left(50 \mu \mathrm{g} \mathrm{mL}^{-1}\right)$ e os clones selecionados em $1 \mathrm{~mL}$ de meio CG CircleGrow (Bio 101 - catalog \# 3000-142) também com ampicilina $\left(50 \mu \mathrm{g} \mathrm{mL}^{-1}\right)$. O cultivo dos clones ocorreu por $22 \mathrm{~h}$ a $37^{\circ} \mathrm{C}$ e $220 \mathrm{rpm}$.

O DNA plasmidial dos clones selecionados foi isolado por miniprep ((Sambrook \& Russell, 2001) e purificado usando plates MultiScreen (Millipore catalog \# MAGVN2250). O material obtido foi quantificado por EBAGE usando gel de agarose $1 \%$, tampão TBE (Tris $89 \mathrm{mM}$; Ácido Bórico $89 \mathrm{mM}$ e EDTA $2.5 \mathrm{mM}$, pH 8,3) contendo brometo de etídeo $\left(0,5 \mu \mathrm{g} \mathrm{mL}^{-1}\right)$, e visualizado em um fotodocumentador Gel Doc 1000, com luz UV (Bio Rad, Richmond, Calif., USA).

O seqüenciamento dos fragmentos ITS inseridos nos plasmídeos foi realizado usando $0,4 \mu \mathrm{L}$ DNA Sequencing-Big Dye Terminator Cycle SequencingReady ABI Prism (Version 3); 3,2 pmols M13/ PUC 1211 forward initiator oligonucleotide (5' GTAAAACGACGGCCAGT - 3'); 100 ng de plasmídeo DNA, 4,6 $\mu \mathrm{L}$ de tampão (400 mM Tris-HCl, pH 9; $10 \mathrm{mM} \mathrm{MgCl}_{2}$ ); e $\mathrm{H}_{2} \mathrm{O}$ mili-Q (Millipore) para um volume final de $10 \mu \mathrm{L}$. A reação foi colocada em um termociclador, MJ Research Inc., modelo PTC-100, com o seguinte programa: 2 min a $96^{\circ} \mathrm{C}$ e 40 ciclos a $96{ }^{\circ} \mathrm{C}$ por $10 \mathrm{~s}, 52{ }^{\circ} \mathrm{C}$ por $20 \mathrm{~s}$, e $60^{\circ} \mathrm{C}$ por 4 min. Os amplicons foram seqüenciados usando o seqüenciador capilar modelo ABI 3700 (Applied Biosystems, Foster City, CA, USA).

\section{Análise das seqüências}

A análise das seqüências foi realizada com o Sequencing Analysis 3.4 e o pacote de programas Phred/Phrap/Consed (Gordon et al., 1998), para permitir verificar a qualidade das seqüências e a existência de possíveis seqüências quiméricas. Somente seqüências com mais de 400 bases e qualidade Phred acima de 20 foram selecionadas com o auxílio de programa Contgen. Nenhuma seqüência foi decartada pelo programa Contgen. As seqüências de nucleotídeos foram comparadas com seqüências do GenBank (acessadas através do NCBI - National Center for Biotechnology Information em 6 de junho de 2003) usando o programa BLAST (Astschul et al.,1997). Após análise das 495 seqüências, elas foram inseridas no banco de dados metagenômico do 
Laboratório de Bioquímica de Microrganismos e Plantas (http://lbmp.fcav.unesp.br/metagenoma), e posteriormente depositadas no GenBank.

Árvores filogenéticas foram construídas com o auxílio dos programas ClustalX (Thompson et al., 1997) para alinhamento global das seqüências e Mega 4 (Tamura et al., 2007) para execução dos cálculos e construção das árvores.

Uma busca no banco de dados metagenômico foi realizada para localizar 58 espécies de rizobactérias citadas na literatura como RPCP (Lucy et al., 2004; Vessey, 2003) pertencentes a quatro filos distintos: Proteobacteria, Firmicutes, Actinobacteria e Cyanobacteria (Vessey et al., 2003; Lucy et al., 2004).

\section{RESULTADOS E DISCUSSÃO}

A técnica molecular de análise do ITS (16S-23S rDNA) foi altamente eficiente na determinação das espécies presentes no solo, detectando um total de 233 bactérias no solo sob mata e 262 no solo sob Eucalyptus sp.

Das 495 seqüências de ITS analisadas, das bibliotecas, de ambos os solos, $19,6 \%$, ou seja, 97 seqüências pertencem a um grupo de oito espécies de rizobactérias promotoras de crescimento de plantas. Os códigos das seqüências (geneids) ITS dessas oito espécies de possíveis RPCP detectadas neste estudo foram depositados no NCBI (AY713465.1, AY713452.1, DQ376549, DQ376546, DQ376547.1 DQ190838.1, DQ190831.1, DQ376548).
Após a comparação das seqüências de rizobactérias de ambos os solos com as seqüências cadastradas no banco internacional de genes (NCBI), foram observadas taxas de similaridade variando de 90 a $99 \%$ entre as RPCP. Somente seqüências com mais de $90 \%$ de similaridade com o Genbank foram consideradas o mesmo organismo. Além disso, as 97 seqüências de RPCP observadas estavam distribuídas diferentemente. Foram encontradas 31 seqüências (6,3\%) dos 495 clones seqüenciados, em solo sob mata e 66 (13,3 \%) em solo sob Eucalyptus sp.

As noventa e sete seqüências de bactérias promotoras de crescimento detectadas nas bibliotecas de ITS pertencem a quatro gêneros: Pseudomonas (com as espécies: $P$. fluorescens e $P$. gladioli), Bacillus (B. subtilis, B. megaterium), Bradyrhizobium (B. japonicum, B. elkanii, Bradyrhizobium sp.) e Frankia (Frankia sp.). Além disso, o solo sob Eucalyptus sp. apresentou maior número de diferentes RPCP que o solo sob mata (Figura 1). Esse resultado está em consonância com observações anteriores de que a diversidade de bactérias no solo sob Eucalyptus sp. é maior do que no solo sob mata (Silveira, 2004; Scaquito, 2004).

Deve-se destacar ainda que as bactérias dos gêneros Bradyrhizobium e Frankia foram as que apareceram em maior proporção entre todos os gêneros nos dois solos analisados, com maiores freqüências no solo sob Eucalyptus sp. (Figura 1).

Por outro lado, as espécies Bacillus subtilis , Bacillus megaterium e Pseudomonas gladioli foram detectadas apenas no solo sob Eucalyptus sp., enquanto Pseudomonas fluorescens apareceram somente no

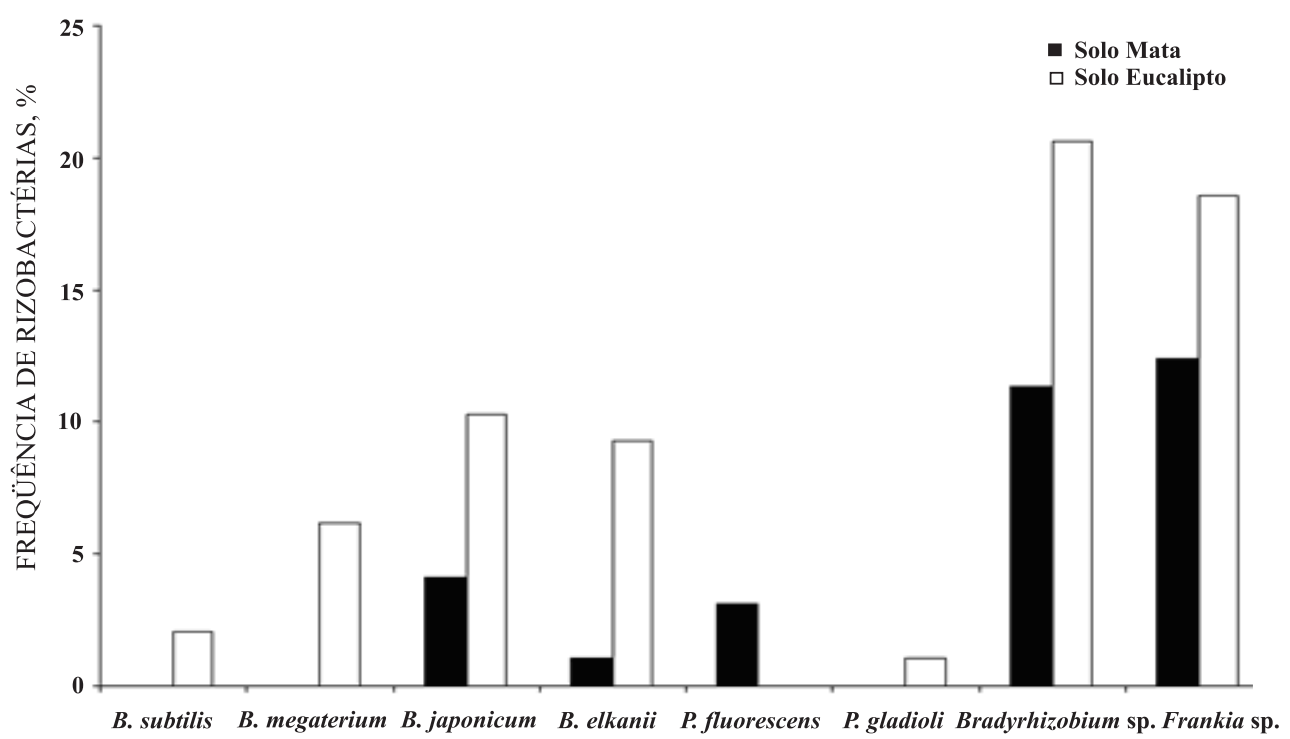

Figura 1. Distribuição de rizobactérias promotoras de crescimento de plantas, observadas nos solos sob mata e sob Eucalyptus sp. B. subtilis (Bacillus subtilis), B.megaterium (Bacillus megaterium), B.japonicum (Bradyrhizobium japonicum), B.elkanii (Bradyrhizobium elkanii), P.fluorescens (Pseudomonas fluorescens) e P. gladioli (Pseudomonas gladioli). 
solo sob mata (Figura 1). Além de Bradyrhizobium japonicum e Bradyrhizobium elkanii, outras seqüências do gênero Bradyrhizobium foram observadas em ambas as bibliotecas, porém com maior freqüência no solo sob Eucalyptus sp. O maior aparecimento de Bradyrhizobium sp. e Frankia sp. nesse solo provavelmente se deve ao fato de muitas bactérias pertencentes a estes gêneros ainda não terem sido classificadas em espécies.

As árvores filogenéticas (Figuras 2 e 3 ) construídas demonstraram que as bactérias se agruparam de acordo com os filos e classes aos quais pertencem, sendo: Pseudomonas fluorescens e Pseudomonas gladioli (Filo: Proteobacteria, classe: Betaproteoacteria); (Filo: Firmicutes) Bacillus subtilis e Bacillus megaterium (Filo: Proteobacteria; classe: Alphaproteoacteria) Bradyrhizobium japonicum, Bradyrhizobium elkanii, Bradyrhizobium sp. e Frankia sp. (Filo: Actinobacteria).

Os resultados obtidos neste trabalho quanto à freqüência de Pseudomonas gladioli e $P$. fluorescens tornam se interessantes considerando-se que isolados bacterianos de Pseudomonas fluorescentes, além de Bacillus e outras bactérias rizosféricas, podem agir como promotores do crescimento de espécies cítricas atuando no crescimento da raiz ou no aumento de matéria seca. Embora a promoção de crescimento do vegetal possa ser afetada de acordo com o ambiente onde se encontram apresentando um comportamento instável (Freitas, 2004), pode-se levantar a hipótese da importância dessas duas rizobactérias no crescimento das espécies vegetais presentes nos solos em estudo.

Aumentos de biomassa e peso seco foram relatados em pinheiros após a inoculação de Pseudomonas fluorescens (Lucy et al., 2004). Possivelmente tal resultado ocorreu devido à ação do fitormônio citocinina sobre a planta, isto porque alterações positivas no crescimento de pinheiro e na quantidade desse fitormônio nas raízes puderam ser detectadas, após a inoculação com esta estirpe bacteriana (Bent et al., 2001). A bactéria Pseudomonas fluorescens também apresenta comprovado auxílio na ectomicorrização de raízes de mudas de Eucalyptus sp., o que auxilia o rápido desenvolvimento destas árvores (Dustan et al., 1998). Além disso, Pseudomonas fluorescens apresenta-se bem versátil ao adaptar-se, com resultados benéficos, às rizosferas de Pinus banksiana (Lucy et al., 2004), Pinus elliottii (Enebak et al., 1998), Picea glauca (Chanway et al., 2000), justificando sua ocorrência em um solo de mata onde há maior diversidade de árvores.

A ocorrência de Bacillus subtilis e Bacillus megaterium no solo sob Eucalyptus sp. poderia indicar uma afinidade com a rizosfera desse tipo de árvore, já que ela não aparece no solo sob mata. Apesar de ter sido observado que a inoculação com Bacillus subtilis não influencia de maneira significativa o aumento de biomassa em árvores de Albedo (spruce) (Shishido \& Chanway, 2000), aumentos de biomassa, da ordem de

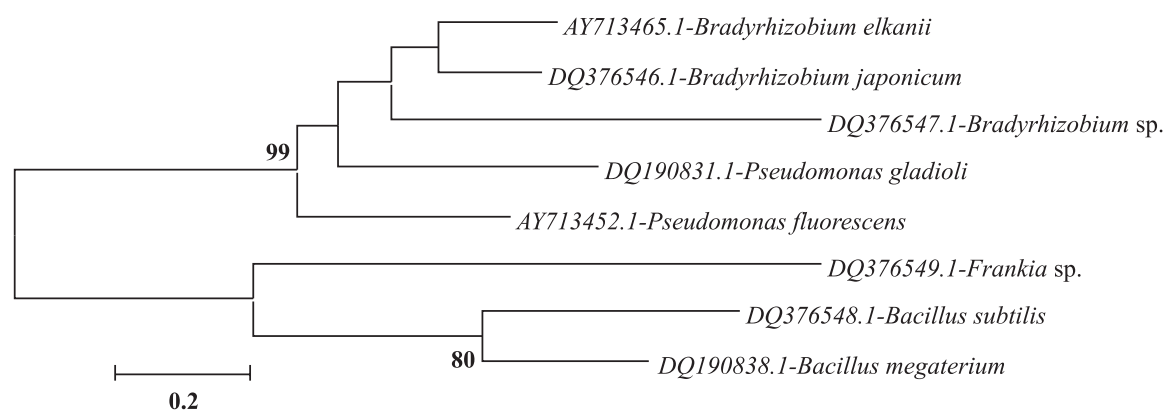

Figura 2. Árvore filogenética construída pelo método Neighobor-Joining com as oito possíveis espécies de RCPC observadas no estudo.

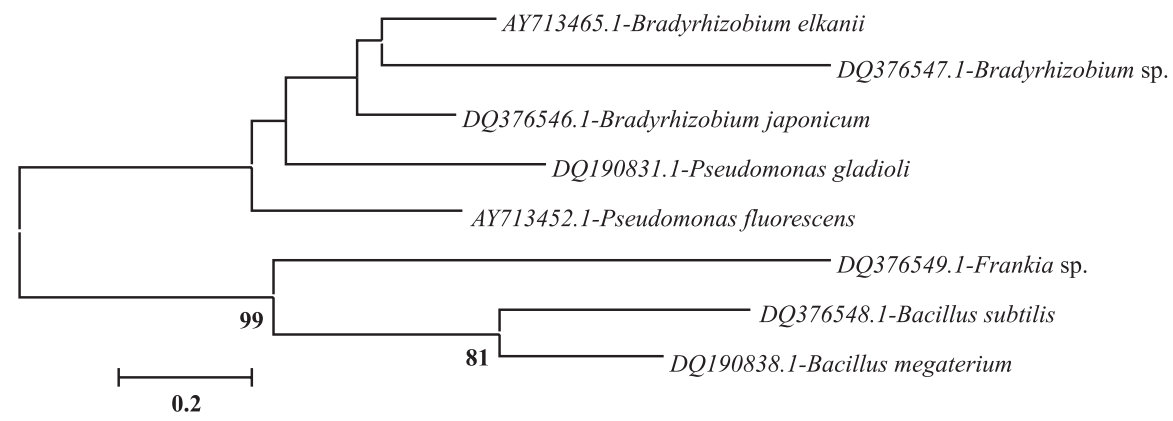

Figura 3. Árvore filogenética construída pelo método da Evolução Mínima (ME) Joining com as oito possíveis espécies de RCPC observadas no estudo. 
$44 \%$, foram encontrados como resultado da inoculação de Bacillus megaterium e Azotobacter chroococcum em experimento com mudas de Eucalyptus sp. em vasos (Lucy et al., 2004).

Outro aspecto importante a mencionar é a indução de resistência à ferrugem do Eucalyptus sp. através da inoculação de Bacillus subtilis no substrato de mudas. Embora não tenha sido o mais eficiente, um moderado grau de indução foi observado (Teixeira, et al., 2005). Ainda nessa linha, Amorin \& Melo (2002) observaram que Bacillus subtilis foi capaz de controlar Phytophthora parasitica e P. citrophthora além de promover maior desenvolvimento tanto da raiz como da parte aérea de plântulas de citros quando comparados à testemunha sem inoculação daquela bactéria.

Como mostrado na figura 1, as espécies Bradyrhizobium sp., Bradyrhizobium japonicum, Bradyrhizobium elkanii e Frankia estavam presentes em ambos os solos, sempre em maior quantidade no solo sob Eucalyptus sp.

Em um extenso estudo realizado em solos australianos cultivados com a leguminosa tropical acácia, foi detectada a presença de Bradyrhizobium elkanii e Bradyrhizobium japonicum, entre outras bactérias, em diferentes regiões do país (Lafay \& Burdon, 2001). A influência que estas bactérias podem ter no desenvolvimento do Eucalyptus sp. é questionável. Por outro lado, a presença de Bradyrhizobium sp. poderia ser conseqüência da presença de leguminosas florestais na mata em estudo, localizada relativamente próxima ao arboreto de Eucalyptus sp.

Dentro desse contexto, o trabalho de Santiago et al. (2002) com Bradyrhizobium sp. mostra que o crescimento de Dalbergia nigra foi igual ao obtido na área onde houve apenas o uso de fertilizantes. Também foi constatado que a inoculação com esta bactéria aumentou a ectomicorrização em Acacia holosericea, favorecendo seu crescimento (André et al., 2005).

Quanto à presença de Frankia em ambos os solos, é justificada pelo fato de que plantas freqüentemente encontradas nas matas, como Angiospermas, hospedam Frankia, em especial árvores do gênero Casuarina e Allocasuarina, que fixam nitrogênio em seus nódulos através da simbiose com essas bactérias, assim como plantas dos gêneros Alnus e Elaeagnus. Do mesmo modo, existe uma grande diversidade de plantas noduladas por Frankia, incluindo mais de 200 espécies distribuídas em 24 gêneros de oito famílias (Marin et al., 1999). Além disso, esta actinobacteria pode viver também na rizosfera e no rizoplano de outras árvores e possui grande habilidade de sobrevivência em diferentes ambientes independentemente do hospedeiro, confirmando assim sua alta promiscuidade simbiótica (Simonet et al., 1998). Esses dados, portanto, possibilitam a compreensão da razão de ter sido Frankia observada em ambos os solos, em freqüência elevadas.
Os dados relatados demonstram uma vez mais a grande variedade de hospedeiros e diferentes hábitats que um simbionte pode ter, o que reforça os resultados coletados neste trabalho com essas mesmas bactérias, ocorrendo em solos sob mata e sob Eucalyptus sp.

Este trabalho forneceu valiosos dados, para futuros estudos, sobre diversidade de populações bacterianas, em especial as rizobactérias promotoras de crescimento de plantas em solos sob diferentes espécies florestais, assim como para o melhor conhecimento das comunidades desses microrganismos nos solos do Brasil. Esses dados podem também fornecer subsídios para novos estudos sobre inoculação de rizobactérias em espécies florestais.

\section{CONCLUSÕES}

1. Constatou-se maior ocorrência de possíveis RPCP no solo sob Eucalyptus sp.

2. Das 495 seqüências de bactérias detectadas, somente 97 eram de rizobactérias, compreendendo oito espécies diferentes detectadas nos dois solos.

\section{AGRADECIMENTOS}

Às agências CAPES, CNPq e FAPESP, que possibilitaram a realização do trabalho.

\section{LITERATURA CITADA}

AMORIM, E.P.R. \& MELO, I.S. Ação antagônica de rizobactérias contra Phytophthora parasitica e $P$ citrophthora e seu efeito no desenvolvimento de plântulas de citros. R. Bras. Frutic., 24:565-568, 2002.

ANDRÉ, S.; GALIANA, A.; LE ROUX, C.; PRIN, Y.; NEYRA, M. \& DUPONNOIS, R. Ectomycorrhizal symbiosis enhanced the efficiency of inoculation with two Bradyrhizobium strains and Acacia holosericea growth. Mycorrhiza, 15:357-364, 2005.

ASTSCHUL, S.F.; MADDEN, T.L.; SCHAFFER, A.A.; ALTSCHUL, S.F.; ZHANG, J.; ZHANG, Z.; MILLER, W. \& LIPMAN, D.J. Gapped BLAST and PSI-BLAST: A new generation of protein database search programs. Nucleic Acids Res., 25:3389-402, 1997.

BENT, E.; TUZUN, S.; CHANWAY, C.P. \& ENEBAK, S. Alterations in plant growth and in root hormone levels of lodgepole pines inoculated with rhizobacteria. Can. J. Microbiol., 47:793-800, 2001.

CHANWAY, C.P.; SHISHIDO, M.; NAIM, J.; JUNGWIRTH, S.; MARKHAM, J.; XIAO, G. \& HOLL, F.B. Endophytic colonization and field responses of hybrid spruce seedlings after inoculation with plant growth-promoting rhizobacteria. For. Ecol. Manag., 133:81-88., 2000. 
CHANWAY, C.P. Differential response of western hemlock from low and high elevations to inoculation with plant growthpromoting Bacillus polymyxa. Soil Biol. Biochem., 27:767-775, 1995 .

CHANWAY, C.P. Inoculation of tree roots with plant growth promoting rhizobacteria: An emerging technology for reforestation. For. Sci., 43:99-112, 1997.

DUNSTAN, W.A.; MALAJCZUK, N. \& DELL, B. Effects of bacteria on mycorrhizal development and growth of container grown Eucalyptus diversicolor F. Muell. Seedlings. Plant Soil, 201:241-249, 1998.

ENEBAK, S.A.; WEI G. \& KLOEPPER, J.W. Effects of plant growth-promoting rhizobacteria on loblolly and slash pine seedlings. For. Sci., 44:139-144, 1998.

FREITAS, S.S. \& VILDOSO, C.I.A. Rizobactérias e promoção do crescimento de plantas cítricas. R. Bras. Ci. Solo, 28:987994, 2004

GORDON, D.; ABAJIAN, C. \& GREEN, P. Consed: A graphical tool for sequence finishing. Genome Res., 8:195-202, 1998.

HOLL, F.B. \& CHANWAY, C.P. Rhizosphere colonization and seedling growth promotion of lodgepole pine by Bacillus polymyxa. Can. J. Microbiol., 38:303-308, 1992.

JUVENAL, T.L. \& MATHOS, R.L.G. Brasil e a importância do reflorestamento. BNDES Setorial, 16:3-30, 2002. Disponível em: <http://www.bndes.gov.br/conhecimento/ bnset/set1601.pdf> Acesso em 3 julho 2006.

LAFAY, B. \& BURDON, J.J. Small-Subunit rRNA Genotyping of Rhizobia NodulatingAustralian Acacia spp. Appl. Environ. Microbiol., 67:396-402, 2001.

LAGUERRE, G.; MAVINGUI, P.; ALLARD, M.R.; CHARNAY, M.P.; LOUVRIER, P.; MAZURIER, S.I.; RIGOTTIERGOIS, L. \& AMARGER, N. Typing of rhizobia by PCR DNA fingerprinting and PCR-restriction fragment length polymorphism analysis of chromosomal and symbiotic gene regions: Application to Rhizobium leguminosarum and its different biovars. Appl Environ. Microbiol., 62:20292036, 1996.

LUCY, M.; REED, E. \& GLICK, B.R. Applications of free living plant growth-promoting rhizobacteria. Antonie Leeuwenhoek, 86:1-25, 2004.

MARIN, V.A.; BALDANI, V.L.D.; TEIXEIRA, K.R.S. \& BALDANI, J.I. Fixação biológica de Nitrôgenio: Bactérias fixadoras de nitrogênio de importância para a agricultura tropical. Seropédica, 1999. 34p. (Série Documentos. Embrapa Agrobiologia)

SAMBROOK, J. \& RUSSELL, D.W. Molecular cloning: A laboratory manual. New York, Cold Spring Harbor Laboratory Press, 2001.

SANTIAGO, G.M.; GARCIA, Q. \& SCOTTI, R.M. Effect of post-planting inoculation with Bradyrhizobium sp. and mycorrhizal fungi on the growth of Brazilian rosewood, Dalbergia nigra Allem. ex Benth., in two tropical soils. New For., 24:15-25, 2002.
SCAQUITO, D.C. Diversidade bacteriana em solos sob mata nativa e Eucalyptus sp. Jaboticabal, Universidade Estadual Paulista, 2004. 80p. (Tese de Mestrado)

SHISHIDO, M. \& CHANWAY, C.P. Colonization and growth of outplanted spruce seedlings pre-inoculated with plant growth promoting rhizobacteria in the greenhouse. Can. J. For.Res., 30:848-854, 2000.

SILVA FILHO, G.N.; NARLOCH, C. \& SCHARF, R. Solubilization of natural phosphates by microorganisms isolated from Pinus and Eucalyptus plantations in Santa Catarina, Brazil. Pesq. Agropec. Bras., 37, n.6, 2002. Disponível em: <http://www.scielo.br/scielo.php?script= sci_arttext\&pid=S0100-204X2002000600014\&lng= en\&nrm=iso>. Acesso em: 26 de Set. de 2008.

SILVEIRA, E.L. Identificação de comunidades bacterianas de solo por sequenciamento do gene 16S rDNA. Jaboticabal, Universidade Estadual Paulista, 2004. 75p (Tese de Mestrado). Disponível em: <http:// www.biblioteca.unesp.br/ bibliotecadigital/document/ get.php/2311/silveira_el_me_jabo.pdf>. Acesso em 3 julho 2006.

SIMONET, P.; NAVARRO, E.; ROUVIER, C.; REDDELL, P.; ZIMPFER, J.; DOMMERGUES, Y.; BARDIN, R.; COMBARRO, P.; HAMELIN, J.; DOMENACH, A.M.; GOURBIÈRE, F.; PRIN, Y.; DAWSON, J.O. \& NORMAND, P. Co-evolution between Frankia populations and host plants in the family Casuarinaceae and consequent patterns of global dispersal. Environ. Microbiol., 1:525533, 1999.

SOTTERO, A.N.; FREITAS, S.S.; MELO, A.M.T. \& TRANI, P.E. Rizobactérias e alface: Colonização rizosférica, promoção de crescimento e controle biológico. R. Bras. Ci. Solo, 30:225-234, 2006.

TAMURA, K.; DUDLEY, J.; NEI, M. \& KUMAR, S. MEGA4: Molecular Evolutionary Genetics Analysis (MEGA) software version 4.0. Molec. Biol. Evol., 24:1596-1599, 2007. <Publicação http://www.kumarlab.net/ publications>. Acesso em 15/06/2008.

TEIXEIRA, D.A.; ALFENAS, A.C.; MAFIA, R.G.; MAFFIA, L.A. \& FERREIRA, E.M. Evidências de indução de resistência sistêmica à ferrugem do Eucalyptus sp. mediada por rizobactérias promotoras do crescimento de plantas. Fitopatol. Bras., 30:350-356, 2005.

THOMPSON, J.D.; GIBSON, T.J.; PLEWNIAK, F.; JEANMOUGIN, F. \& HIGGINS, D.G. The ClustalX windows interface: Flexible strategies for multiple sequence alignment aided by quality analysis tools. Nucleic Acids Res., 25:4876-4882, 1997.

VESSEY, J.K. Plant growth promoting rhizobacteria as biofertilizers. Plant Soil, 255:571-586, 2003.

ZAADY, E. \& PEREVOLTSKY, A. Enhancement of growth and establishment of oak seedlings Quercus ithaburensis Decaisne by inoculation with Azospirillum brasilense. For. Ecol. Manag., 72:81-83, 1995. 